\title{
Microalgae biomass interaction in biopolymer gelled systems
}

\author{
A.P. Batista ${ }^{a, b, *}$, M.C. Nunes ${ }^{\text {a }}$, A. Raymundo ${ }^{\text {a }}$, L. Gouveia ${ }^{b}$, I. Sousa ${ }^{c}$, F. Cordobés ${ }^{d}$, \\ A. Guerrero ${ }^{\mathrm{d}}$, J.M. Franco ${ }^{\mathrm{e}}$ \\ ${ }^{a}$ Núcleo de Investigação de Eng. ${ }^{a}$ Alimentar e Biotecnologia, Instituto Piaget, ISEIT de Almada, Quinta da Arreinela de Cima, 2800-305 Almada, Portugal \\ ${ }^{\mathrm{b}}$ Laboratório Nacional de Energia e Geologia (LNEG), Unidade de Bioenergia, Estrada do Paço do Lumiar, 1649-038 Lisboa, Portugal \\ ${ }^{c}$ Instituto Superior de Agronomia, DAIAT, Universidade Técnica de Lisboa, Tapada da Ajuda, 1349-017 Lisboa, Portugal \\ d Universidad de Sevilla, Facultad de Química, Dpto. Ingenieria Química, Prof. Garcia Gonzalez, 41012 Sevilla, Spain \\ ${ }^{\mathrm{e}}$ Universidad de Huelva, Faculdad de Ciências Experimentales, Dpto. Ingeniería Química, Campus del Carmen, 21071 Huelva, Spain
}

\section{A R T I C L E I N F O}

\section{Article history:}

Received 1 April 2010

Accepted 24 September 2010

\section{Keywords:}

Microalgal biomass

Spirulina

Haematococcus

Pea protein

kappa-Carrageenan

Starch

Gels

\begin{abstract}
A B S T R A C T
Microalgae are an enormous biological resource, representing one of the most promising sources for the development of new food products and applications. Pea protein/ $\kappa$-carrageenan/starch gels, interesting vegetarian alternatives to dairy desserts, served as model systems to study the addition of microalgal biomass, its effect, and subsequent rheological behaviour. Spirulina and Haematococcus gels presented a markedly different rheological behaviour compared to the control mixed biopolymer gelled system. The present goal is to clarify how these microalgae affect the gelation and interact with each biopolymer present in the complex mixed gel system. Hence, the aim of the present work is to study the effect of Spirulina and Haematococcus microalgal biomass addition on the rheological behaviour of pea protein, $\kappa-$ carrageenan and starch simple gels, as well as in pea protein/ $\kappa$-carrageenan and pea protein/starch systems. The gelation process was monitored in-situ through dynamic oscillatory measurements (temperature, time and frequency sweep tests) for a $24 \mathrm{~h}$ maturation period, and rheological results were supported with fluorescence optical microscopy observations. The addition of Spirulina and Haematococcus to biopolymer gelled systems induced significant changes in the gels' rheological behaviour and microstructure. In general, it was observed that the gelling mechanism is ruled by the biopolymers, while microalgae seem to be embedded in the gel network acting as active particle fillers. The addition of Haematococcus resulted in more structured gels in comparison to the control and Spirulina systems. In the case of $\kappa$-carrageenan gels, both microalgae induced a large increase in the rheological parameters, which should be related to the high ionic content of microalgal biomass. Spirulina addition on starch systems promoted a decrease in the gels' rheological parameters. This should be related to the starch gelatinization process, probably by competing for water binding zones during the granules' hydration process.
\end{abstract}

(c) 2010 Elsevier Ltd. All rights reserved.

\section{Introduction}

Microalgae are an enormous biological resource, representing one of the most promising sources for the development of new products and applications. They can be used to enhance the nutritional value of food and animal feed, due to their well balanced chemical composition.

Spirulina (Arthrospira) is a microscopic filamentous prokaryotic alga (cyanobacteria), which has been used in the human diet for at

\footnotetext{
* Corresponding author at: Núcleo de Investigação de Eng. a Alimentar e Biotecnologia, Instituto Piaget, ISEIT de Almada, Quinta da Arreinela de Cima, 2800 305 Almada, Portugal. Tel.: +351 2129462 50; fax: +351 212946251 .

E-mail address: pbatista@almada.ipiaget.org (A.P. Batista).
}

least 700 years. Its origins date back to the Native Americans (lake Texcoco, Mexico) and Africans (lake Chade), where it was used as an alternative source of protein (protein content $>50 \%$ ). Nowadays, it is broadly used as a dietary food supplement worldwide, due to its balanced composition in terms of essential amino acids, essential fatty acids (e.g. $\gamma$-linolenic acid), phycobiliproteins, vitamins (e.g. $\mathrm{B}_{12}$ ) and minerals. Spirulina has between 15 and $25 \%$ of total carbohydrates, with glycogen being the main storage sugar. Peptidoglycan, a polymer made of sugars ( $\beta-1,4-N$-acetylglucosamine and $\mathrm{N}$-acetylmuramic acid) and amino acids, forms a mesh-like layer outside the plasma membrane of the cyanobacteria, thus forming cell walls similar to Gram positive bacteria (Belay, 2008).

Haematococcus pluvialis is a unicellular eukaryotic green alga and the organism known to accumulate the highest level of 
astaxanthin in nature $(1.5-3.0 \% \mathrm{dw})$ (Todd-Lorenz \& Cysewski, 2000). When green vegetative cells come across stress conditions (e.g. nitrogen deficiency, high light intensity, salt addition) the alga rapidly differentiates into encysted cells which accumulate astaxanthin in fat globules (usually esterified with oleic acid) outside the chloroplast. This carotenogenesis process induces large changes in the microalgal cell composition, namely lowering the protein and increasing the lipid contents. The encysted cell walls are mainly composed of carbohydrates (hexoses), cellulose and proteins, and the main storage sugar within the cell is starch. It has been suggested that the accumulated astaxanthin might function as a protective agent against oxidative stress damage (Kobayashi et al., 1997). This carotenoid pigment has been primarily used for fish (e.g. salmon, trout) and shrimp pigmentation in aquaculture. Currently, the primary Haematococcus production target is focused in its potential nutraceutical use.

Freeze-dried biomass of various microalgae has been successfully used as a colouring agent and as a source of $\omega_{3}$ polyunsaturated fatty acids in model food products developed by our research group, such as oil-in-water emulsions (Gouveia, Batista, Raymundo, Sousa, \& Empis, 2006; Raymundo, Gouveia, Batista, Empis, \& Sousa, 2005), vegetable puddings (Batista, Gouveia, Nunes, Franco, \& Raymundo, 2008; Gouveia, Batista, Raymundo, \& Bandarra, 2008), biscuits (Gouveia, Batista, Miranda, Empis, \& Raymundo, 2007; Gouveia, Coutinho, et al., 2008) and pasta (Fradique et al., 2010). It has been observed that besides colouring and nutritional purposes, the addition of microalgal biomass to food systems imparts significant changes in its microstructure and rheological properties.

Most food products have a complex composition, including at least three biopolymer types whose interaction determines the products' structural and mechanical properties (Tolstoguzov, 2003). The impact of microalgae addition in different food matrixes reflects their interactions with other food components such as biopolymers (e.g. proteins and polysaccharides).

Recently, pea protein/ $\kappa$-carrageenan/starch gel systems have been extensively studied as an interesting alternative to dairy desserts (Nunes, Raymundo, \& Sousa, 2006a, 2006b). Recent research (Batista, Gouveia, et al., 2008), has shown that these biopolymer gels served as model systems to study the effect of five different microalgae on the rheological behaviour of these gels. Spirulina and Haematococcus gels presented very different rheological properties compared to other algae (Chlorella vulgaris and Diacronema vlkianum) and the control gel. Haematococcus promoted a structural reinforcement expressed by improved rheological properties, while the addition of Spirulina promoted a reduction in the rheological parameters of the gels. To continue with this research, this study's goal is to clarify how these two microalgae influence and interact with each biopolymer present in the complex mixed gel system - pea protein, $\kappa$-carrageenan and starch in aqueous media through dynamic rheology and microscopy measurements.

\section{Materials and methods}

\subsection{Microalgae production}

Spirulina maxima (Sp) and Haematococcus pluvialis ( $\mathrm{Hp}$ ) microalgae were produced at the LNEG - Bioenergy Unit (Lisbon). The microalgae were cultivated in appropriate growth media (Vonshak, 1986), in airlift bioreactors with bubbling air, under low light conditions $\left(150 \mu \mathrm{Em}^{-2} \mathrm{~s}^{-1}\right)$, and optimal growth temperatures (Sp: $\left.34^{\circ} \mathrm{C} ; \mathrm{Hp}: 25^{\circ} \mathrm{C}\right)$. Spirulina was harvested during the stationary phase, while Haematococcus was first submitted to a carotenogenesis process by nitrogen starvation, $\mathrm{NaCl}$ addition, and high luminosity enhanced by culture dilution (Gouveia \& Empis, 2003), before being harvested. Microalgal biomass was harvested by simply stopping agitation, concentrated by centrifugation and freeze drying.

The gross chemical composition (\% dw) of the microalgal biomass is (Batista, Gouveia, et al., 2008):

- Sp: $44.9 \%$ protein; 3.6\% fat; $16.6 \%$ carbohydrates; $30.9 \%$ ashes (2.1\% K; $0.8 \% \mathrm{Ca} ; 0.3 \% \mathrm{Mg} ; 7.0 \% \mathrm{Na})$;

- Hp: $10.2 \%$ protein; $40.7 \%$ fat; $33.6 \%$ carbohydrates; $8.9 \%$ ashes (0.9\% K; $0.2 \% \mathrm{Ca} ; 0.2 \% \mathrm{Mg} ; 5.5 \% \mathrm{Na})$.

\subsection{Gel preparation}

Pea protein isolate (Pisane $\mathrm{F}{ }^{\circledR}$, Cosucra, Belgium), $\kappa$-carrageenan (Satiagel AMP45 ${ }^{\circledR}$, Degussa, France) and native maize starch (Vitena $A^{\circledR}$, Copam, Portugal) biopolymers were used to study microalgae interactions in gelled systems. All these ingredients were kindly provided by the respective manufacturers.

Biopolymer model systems were prepared at a concentration near to the critical gelling concentration for each biopolymer: pea protein $12 \%$, $\kappa$-carrageenan $0.75 \%$, starch $5.0 \%$ (all percentages are $\mathrm{w} / \mathrm{w})$. Pea protein $(4 \%) / \kappa$-carrageenan $(0.15 \%)$ and pea protein $(6 \%) /$ starch $(3.75 \%)$ binary systems were also studied.

Microalgal biomass was added to these systems in the same proportion for each biopolymer as in a mixed gel final formulation proposed and optimized in previous studies (Batista, Gouveia, et al., 2008; Nunes et al., 2006a, 2006b): $4 \%$ pea protein isolate, $0.15 \% \kappa-$ carrageenan, $2.5 \%$ maize starch, $0.75 \%$ microalgal biomass. Accordingly, the compositions of the systems presently studied were:

- pea protein $12 \%$ + microalga $2.25 \%$ (pH: C 6.5-Sp 8.3-Hp 6.6);

- $\kappa$-carrageenan 0.75\% + microalga 3.75\% (pH: 8.6-9.0-6.6);

- starch 5\% + microalga 1.5\% (pH: 5.7-8.8-6.1);

- pea protein $4 \%+\kappa$-carrageenan $0.15 \%+$ microalga $0.75 \%(\mathrm{pH}$ : 6.9-6.8-6.7);

- pea protein $6 \%+$ starch $3.75 \%+$ microalga $1.125 \% \quad(\mathrm{pH}$ : 6.7-8.3-6.7).

The ingredients were dispersed in demineralised water by mechanical agitation $(300 \mathrm{rpm}, 1 \mathrm{~h})$ at room temperature. No adjustments were made to the natural $\mathrm{pH}$ of the systems (indicated above for control- $\mathrm{Sp}-\mathrm{Hp}$ ) and no salts were added to the systems, in order for the ionic content of the dispersions to only be due to the salts present in the biopolymers and microalgae.

\subsection{Rheological measurements}

The gelation process was monitored in-situ in a controlled stress rheometer (RS-300, Haake, Germany) coupled to an UTC-Peltier system, using cone-plate geometry $\left(\mathrm{C} 35 / 2^{\circ}\right)$, through dynamic small amplitude oscillatory shear measurements (SAOS). The samples were heated from $20^{\circ} \mathrm{C}$ to $90^{\circ} \mathrm{C}$, maintained at this temperature for $5 \mathrm{~min}$, and then cooled down to $5^{\circ} \mathrm{C}$, at $1{ }^{\circ} \mathrm{C} / \mathrm{min}$ $(\omega=6.28 \mathrm{rad} / \mathrm{s})$, according to previously optimized gel setting conditions for these systems (Batista, Nunes, et al., 2008; Batista et al., 2009). Subsequently, time sweep tests were conducted at $5{ }^{\circ} \mathrm{C}$ during $24 \mathrm{~h}(\omega=6.28 \mathrm{rad} / \mathrm{s})$ followed by frequency sweep tests $(\omega=0.01-111.7 \mathrm{rad} / \mathrm{s})$. All tests were carried out at stress values within the linear viscoelastic region. The samples were covered with paraffin oil to prevent moisture loss.

\subsection{Fluorescence microscopy}

The gels were analysed by fluorescence microscopy using an Olympus BX61 optical microscope in epifluorescence mode with 


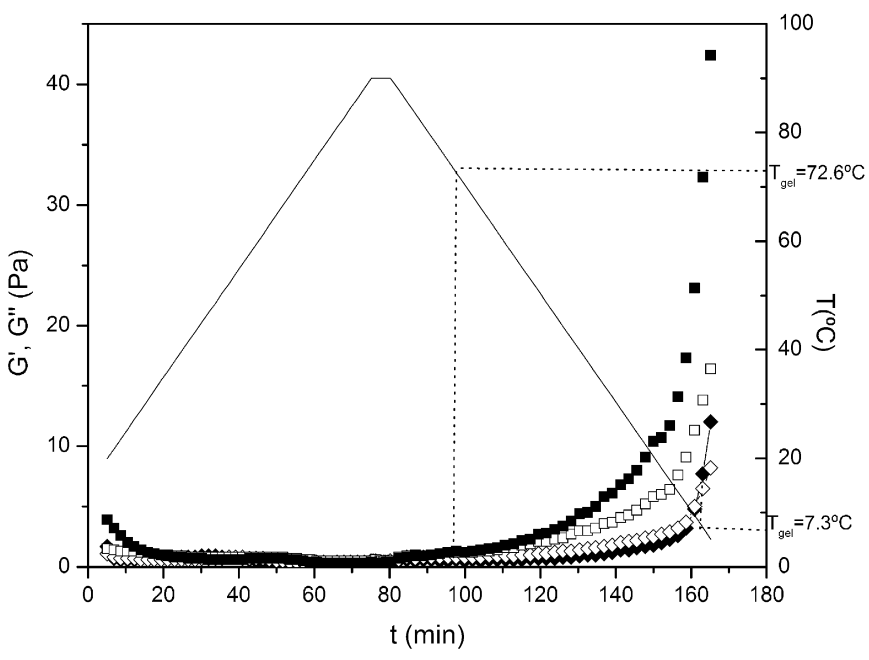

Fig. 1. Evolution of the viscoelastic functions $\mathrm{G}^{\prime}$ (closed symbol) and $\mathrm{G}^{\prime \prime}$ (open symbol), of $12 \%$ pea protein dispersions along thermal treatment $(\mathrm{T}-$ line).
$4 \times$ and $10 \times$ (UPlanApo) objectives lenses. A Mercury arc lamp was used as an excitation source and DAPI, TRITC, FITC fluorescence filter sets were used to select different excitation and emission wavelengths.

After thermal treatment, samples were poured between a microscope slide and a coverslip, sealed with varnish to prevent dehydration, and kept in a refrigerator at $5-7^{\circ} \mathrm{C}$ for a $24 \mathrm{~h}$ period to allow gel maturation.

Spirulina, Haematococcus and pea protein presented autofluorescence. Starch was non-covalently stained with Rhodamine B (Sigma), in the absence of pea protein. Rhodamine was added during the mechanical dispersion of the biopolymers at a $0.002 \%$ concentration level.

\section{Results and discussion}

\subsection{Microalgae-pea protein systems}

Pea protein dispersions at $12 \%$ appear to be near the limitingconcentration for gelling to occur (Batista, Portugal, Sousa, Crespo, \& Raymundo, 2005; Nunes, 2005). In some experiments (replicates), the gel formed was sometimes weaker and at other times stronger suggesting that at this concentration level the gels were
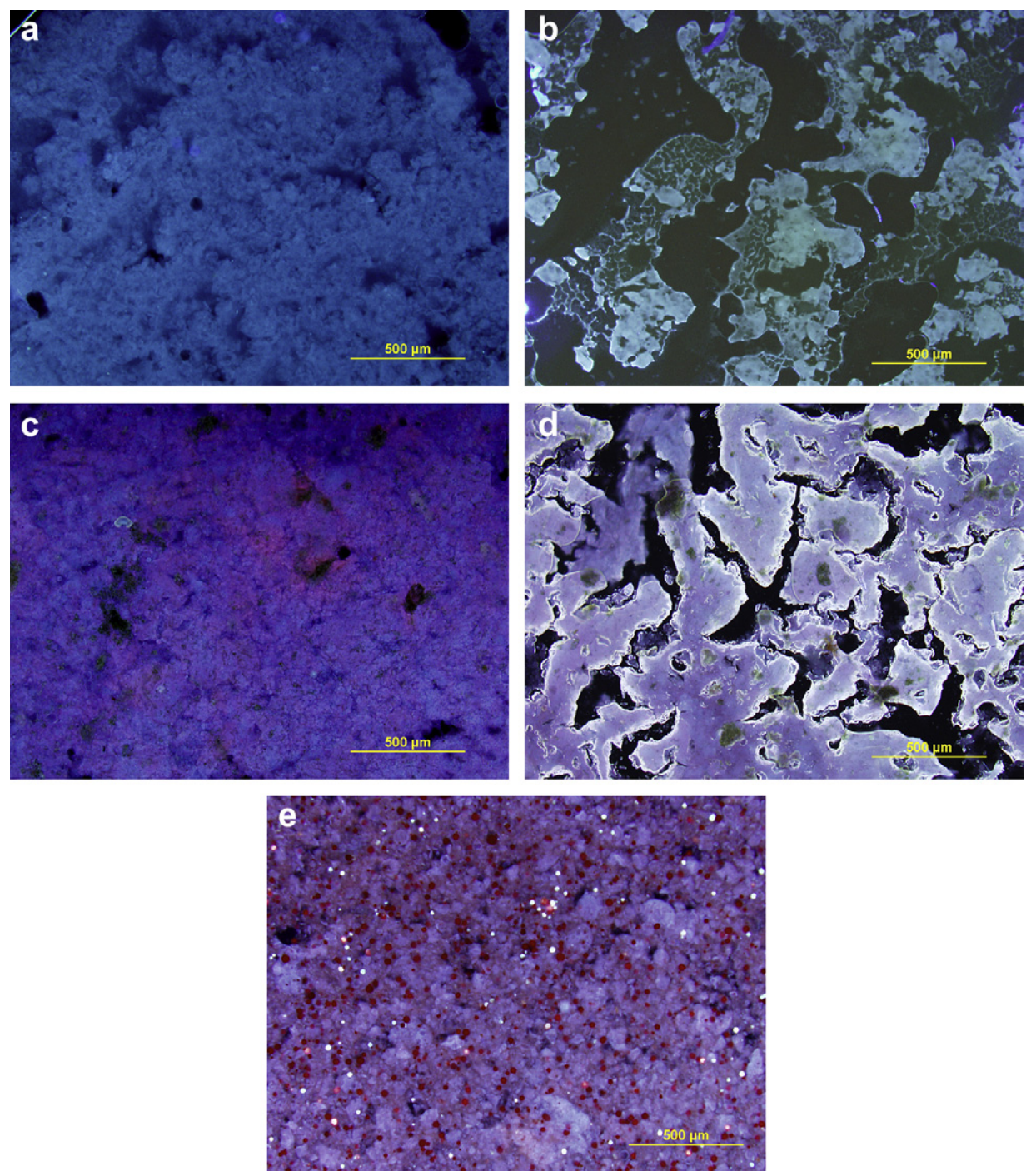

Fig. 2. Fluorescence microscopy images of $12 \%$ pea protein gel systems (a-b) with $2.25 \%$ Spirulina (c-d) and Haematococcus (e) microalgal biomass addition (DAPI filter). 
not formed in a systematic manner. This has also been reported by Batista et al. (2005) when pea protein dispersions at $12.5 \%$ gelled in the rheometer device but not in the refrigerator. Fig. 1 presents the evolution of the viscoelastic moduli along thermal treatment for different replicas of $12 \%$ pea protein dispersion samples. A decrease in $G^{\prime}$ and $G^{\prime \prime}$, when heating the samples from $20^{\circ} \mathrm{C}$ up to $90^{\circ} \mathrm{C}$, was followed by an increase when cooling to $5^{\circ} \mathrm{C}$. This is the general behaviour of gels from globular protein systems, as reported by several authors (e.g. Van Vliet, Martin, \& Bos, 2002). However, it is clear that different sol-gel transition $\left(G^{\prime}>G^{\prime \prime}\right)$ temperatures were found for replicates of the same material system. In one replicate, the transition was identified at $73{ }^{\circ} \mathrm{C}$, whereas in another replicate the transition was detected at only $7.3^{\circ} \mathrm{C}$, resulting in a much weaker gel. This can be confirmed by the microscope photographs in Fig. 2, where one image (Fig. 2a) shows a continuous dense network of protein aggregates (bright areas) and the other a discontinuous and disrupted structure (Fig. 2b).

When Spirulina was added to the above system, a slight reinforcement of the pea protein gel structure was observed (Fig. 2c-d), i.e. the brighter density of the red areas on the picture, especially when comparing Fig. 2b with Fig. 2d. This reinforcement of the gel structure is confirmed by the rheological results shown in Fig. 3b, where $G^{\prime}$ and $G^{\prime \prime}$ values are slightly higher for the pea protein/ Spirulina binary gel. In general, the microalgae appear to be embedded (red colored) within the protein network and much denser in the case of Haematococcus (Fig. 2e).
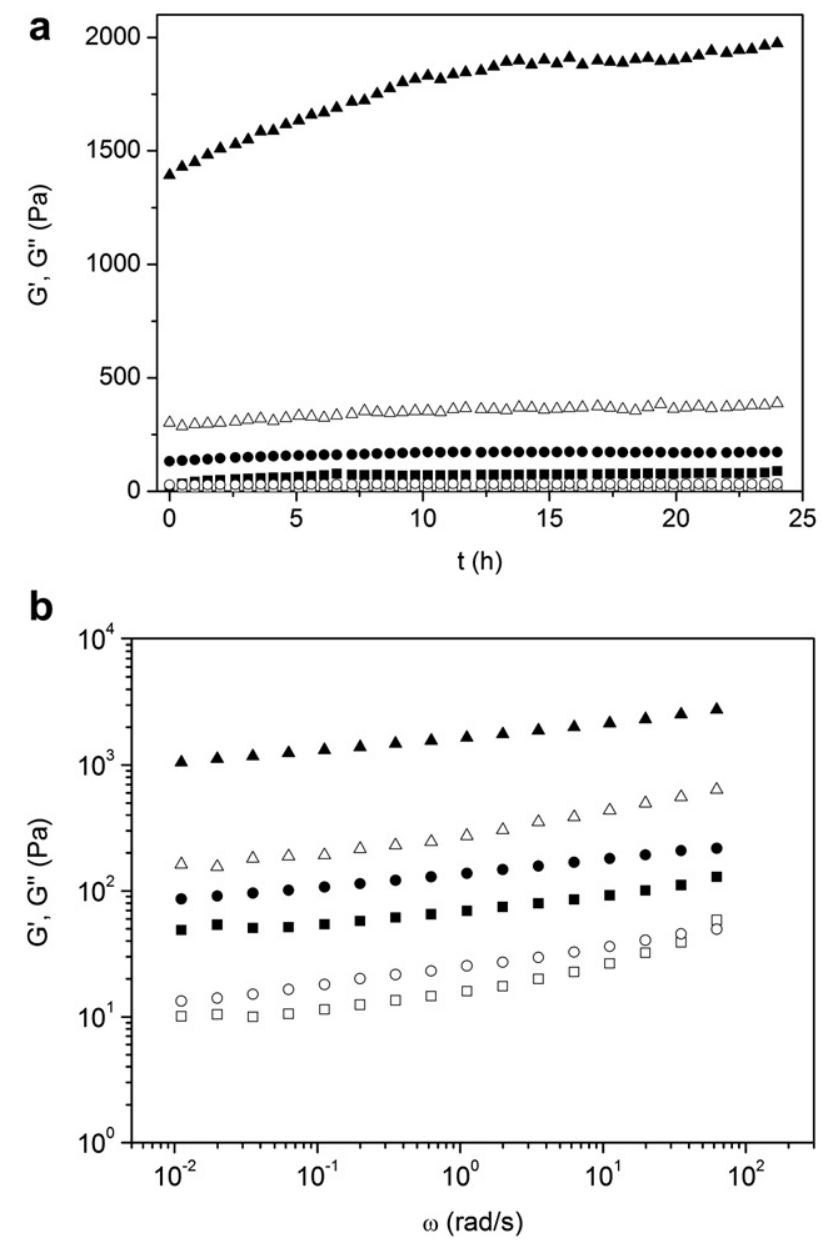

Fig. 3. (a) Temperature and maturation kinetics curves (a) and mechanical spectra (b) at $5{ }^{\circ} \mathrm{C}$, of $12 \%$ pea protein gel systems $(\boldsymbol{\square})$ with $2.25 \%$ Spirulina $(\boldsymbol{O})$ and Haematococcus ( $\mathbf{\Delta}$ ) microalgal biomass addition. $\mathrm{G}^{\prime}$ (closed symbol), $\mathrm{G}^{\prime \prime}$ (open symbol).
Adding Haematococcus causes a much more pronounced reinforcement of gel strength, as can be observed from the rheological data from Fig. 3. In general, gel maturation kinetic curves are characterized by a marked increase in $G^{\prime}$ in the first few hours, followed by a slower evolution of this modulus along time. This behaviour is typical of biopolymer gelation processes (Clark, Kavanagh, \& Ross-Murphy, 2001), where there is a continuous reorganization of the gel network due to the formation and rupture of entanglements between the polymeric chains of the macromolecules. At the end of the $24 \mathrm{~h}$ maturation period the pea protein-Haematococcus system presented a $\mathrm{G}^{\prime}$ value around $2000 \mathrm{~Pa}$, one order of magnitude higher than the pea protein simple gel and the pea protein-Spirulina gel system (Fig. 3a). These results are well supported by the mechanical spectra (Fig. 3b), where it is observed that, in all cases, $G^{\prime}$ is higher than $G^{\prime \prime}$ although a stronger gel is obtained by adding Haematococcus. However, the SAOS functions frequency dependence is not modified by microalgae addition, indicating that pea protein is the dominant biopolymer in the gel network.

The impact of microalgal biomass addition can be related to modifications in the $\mathrm{pH}$ and salt content of the gels, by affecting pea protein electrostatic interactions during the aggregation mechanism. These should be more relevant in the case of Spirulina biomass which presents higher ionic content and a higher $\mathrm{pH}$. However, $\mathrm{pH}$ values are always above pea protein isoelectric point (4.5), not affecting the global charge of this biopolymer which
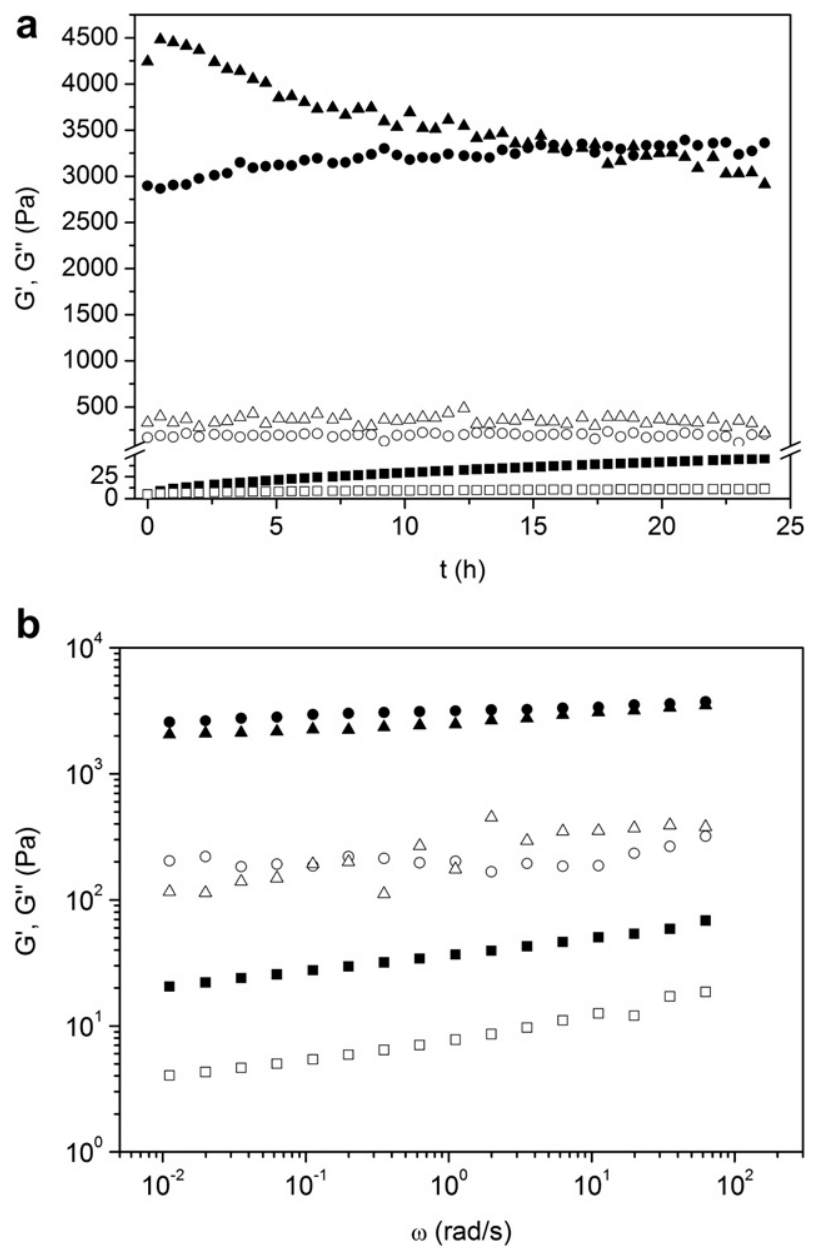

Fig. 4. Maturation kinetics curves (a) and mechanical spectra (b) at $5{ }^{\circ} \mathrm{C}$, of $0.75 \% \mathrm{~K}$ carrageenan gel systems ( $\mathbf{\square})$ with $3.75 \%$ Spirulina $(\bullet)$ and Haematococcus ( $(\boldsymbol{\Delta})$ microalgal biomass addition. $G^{\prime}$ (closed symbol), $G^{\prime \prime}$ (open symbol). 

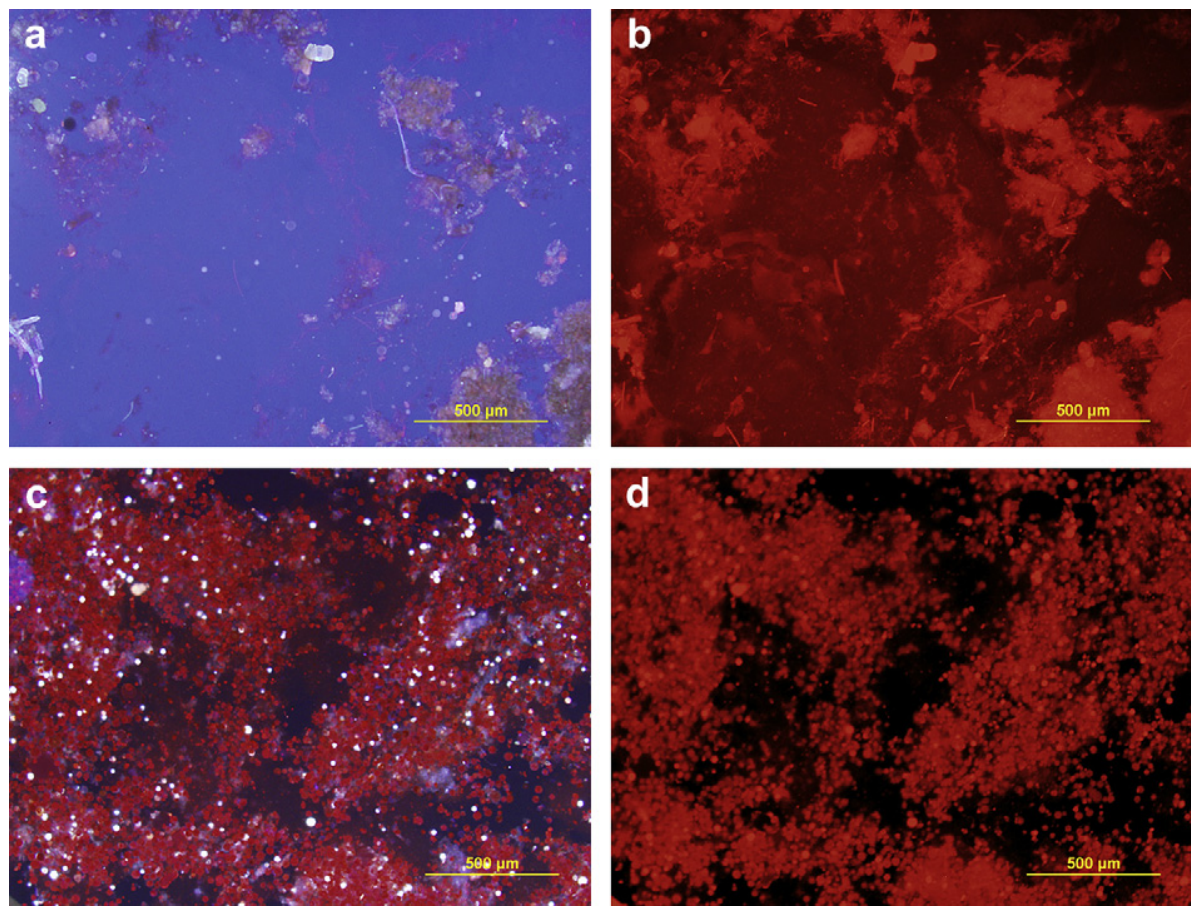

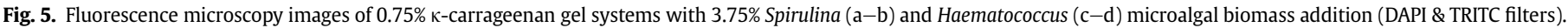

remains negative. In the case of Haematococcus, the structural reinforcement action could also be related to its high fat content (41\%) (Batista, Gouveia, et al., 2008). The influence of fat content on gelling behaviour has been studied in milk gelled systems, such as acid milk gels (Houzé, Cases, Colas, \& Cayot, 2005; Lucey, Munro, \& Singh, 1998) and dairy custard model systems (Vélez-Ruiz, González-Tomás, \& Costell, 2005) from which it was concluded that using full fat milk rather than skimmed milk resulted in stronger gels. The modification on the rheological properties of fatcontaining gels is usually attributed to fat droplets acting as active filler particles embedded in the protein matrix.

\subsection{Microalgae- $\kappa$-carrageenan systems}

$\kappa$-Carrageenan forms a very weak gel at $0.75 \%$ which should be near its critical gelling concentration (Nickerson \& Paulson, 2004; Nunes, 2005) in the absence of added ions. The sol-gel transition of $\kappa$-carrageenan dispersions is characterized by a sharp increase in $\mathrm{G}^{\prime}$ upon cooling, and in parallel with a marked decrease in phase angle $(\delta)$ (Nunes, 2005). For the $\kappa$-carrageenan $0.75 \%$ system, this transition occurred in the $5-7^{\circ} \mathrm{C}$ temperature range. However, when adding Spirulina and Haematococcus the gelation temperature increased to $30^{\circ} \mathrm{C}$ and $25^{\circ} \mathrm{C}$, respectively (results not shown). This means that gel formation occurs earlier during the cooling process, making it possible to obtain $\kappa$-carrageenan gels at room temperature through the addition of microalgae biomass. In all cases, the resulting microalgae $-\kappa$-carrageenan maturated gels presented impressively enhanced rheological properties, with $G^{\prime}$ values two orders of magnitude higher than the simple $\kappa$-carrageenan gel (Fig. 4a). However, Haematococcus gel maturation curves are not typical, showing a decrease in $\mathrm{G}^{\prime}$, probably because the gel was too hard and brittle, disturbing the rheological data measurement. The mechanical spectra of these systems is presented in Fig. $4 \mathrm{~b}$, confirming the strong nature of the gel imparted by both microalgae.

$\kappa$-Carrageenan gels are formed through intermolecular association (junction zones) of double helices into stable structured aggregates (Morris, Rees, \& Robinson, 1980). The formation and
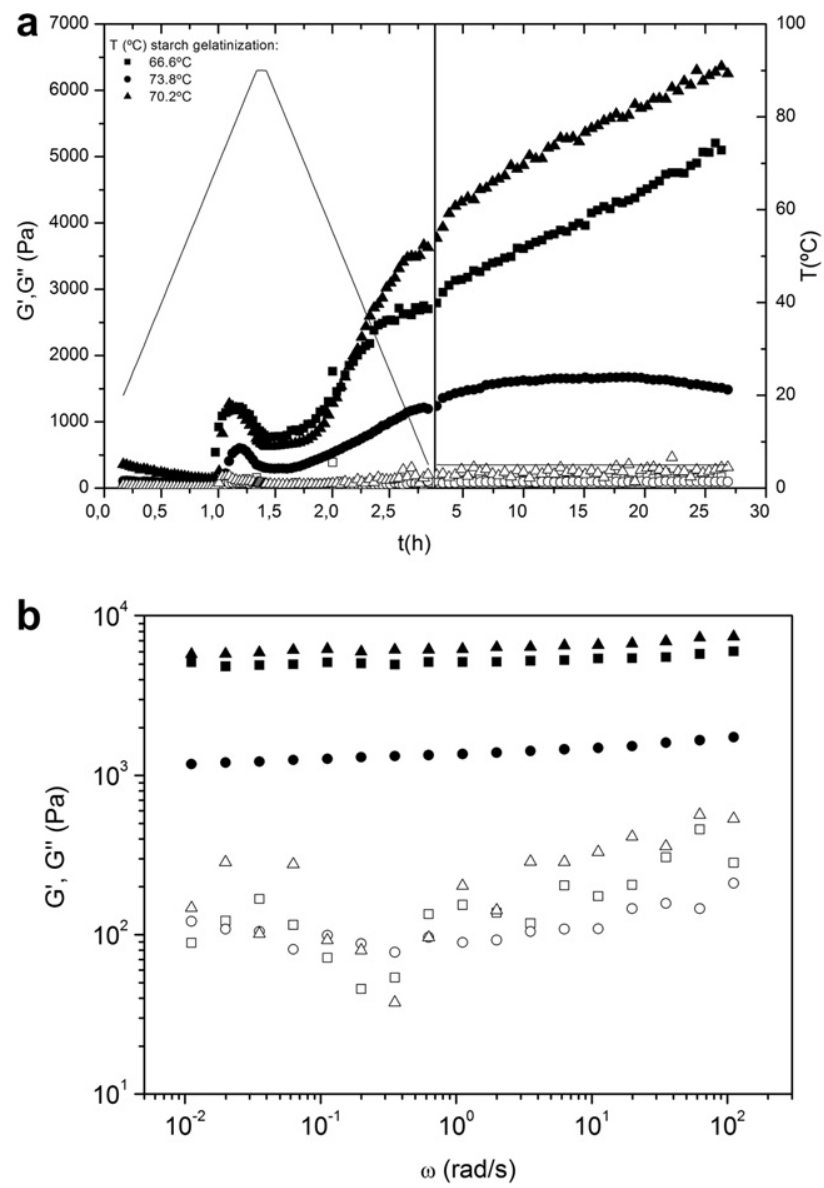

Fig. 6. Evolution of $\mathrm{G}^{\prime}$ and $\mathrm{G}^{\prime \prime}$ along thermal treatment and $24 \mathrm{~h}$ maturation at $5{ }^{\circ} \mathrm{C}$ (a); and mechanical spectra (b), of 5\% starch gel systems ( $)$ with $1.5 \%$ Spirulina $(\bullet)$ and Haematococcus ( $\boldsymbol{\Lambda}$ ) microalgal biomass addition. $\mathrm{G}^{\prime}$ (closed symbol), $\mathrm{G}^{\prime \prime}$ (open symbol). $\mathrm{T}$ (line). 

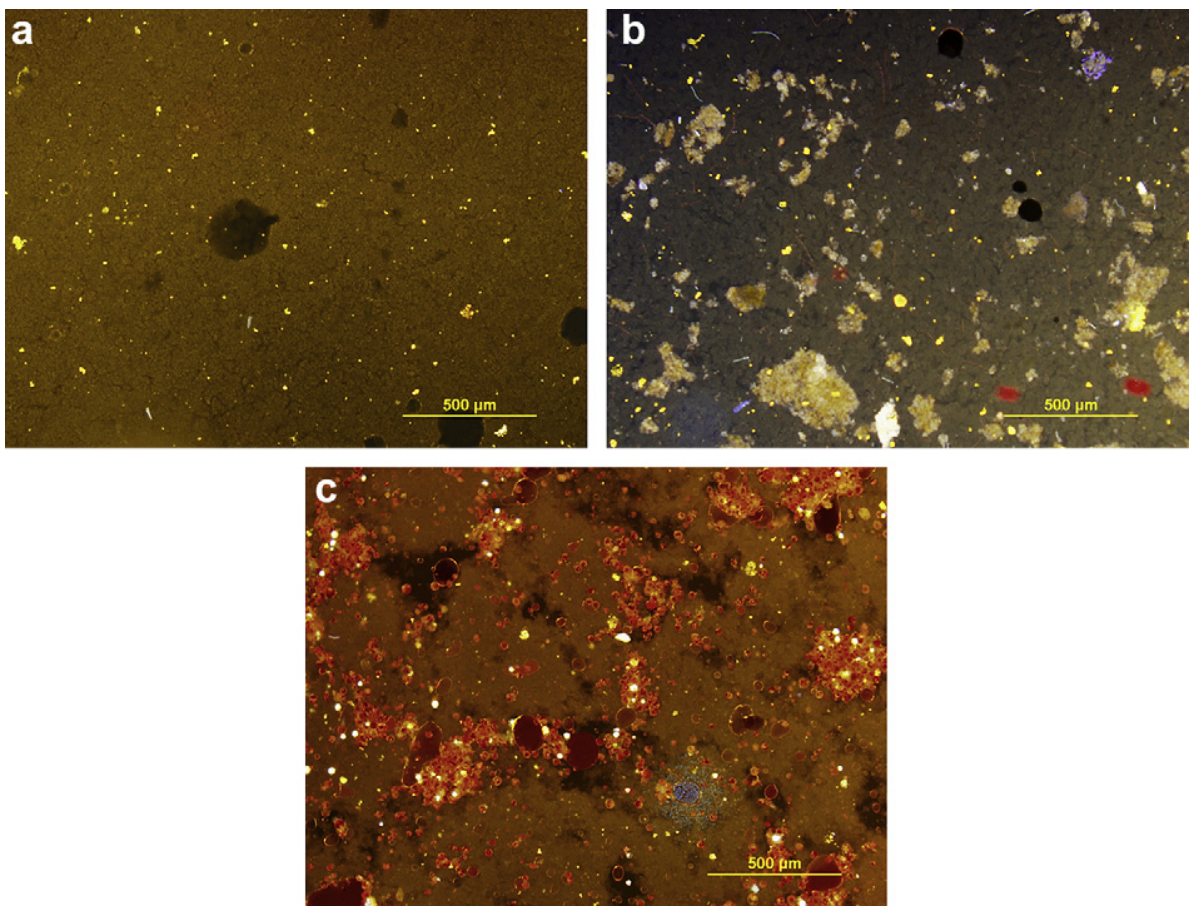

Fig. 7. Fluorescence microscopy images of $5 \%$ starch gel systems (a) with $1.5 \%$ Spirulina (b) and Haematococcus (c) microalgal biomass addition (DAPI filter).

aggregation of these double helices is induced by cooling and is highly dependent on the presence of electrolytes even at very low concentrations (Morris et al., 1980; Rochas \& Landry, 1987). Potassium cations $\left(\mathrm{K}^{+}\right)$have a specific affinity to $\kappa$-carrageenan and are usually the most effective in inducing gellification, followed by divalent cations such as $\mathrm{Ca}^{2+}$ and then by other monovalent cations such as $\mathrm{Na}^{+}$(Chen, Liao, \& Dunstan, 2002).

Microalgal biomass contains significant amounts of minerals (see Section 2.1), derived from its intrinsic chemical composition and from culture media residues. Systems with $0.75 \%$ к-carrageenan and $3.75 \%$ microalgal biomass include $0.08 \% \mathrm{~K}^{+}(0.02 \mathrm{M})$, $0.03 \% \mathrm{Ca}^{2+}(0.01 \mathrm{M})$ and $0.26 \% \mathrm{Na}^{+}(0.1 \mathrm{M})$ for Spirulina and $0.03 \%$ $\mathrm{K}^{+}(0.01 \mathrm{M}), 0.01 \% \mathrm{Ca}^{2+}(0.002 \mathrm{M})$ and $0.21 \% \mathrm{Na}^{+}(0.1 \mathrm{M})$ for Haematococcus. This can explain the contribution of microalgal addition to the huge increase in $\kappa$-carrageenan gels rheological moduli. This is in agreement with previous research conducted by other authors, such as Chen et al. (2002) where the formation of very weak $\kappa$-carrageenan gels was observed for concentrations between $0.7 \%$ and $1.4 \%$ in the absence of salts. After the addition of low levels of potassium and calcium, the gels rheological moduli $\left(G^{\prime}, G^{\prime \prime}\right)$ increased considerably, indicating a higher degree of gel structure.

$\kappa$-Carrageenan-microalgae gel structures can be observed in Fig. 5. $\kappa$-Carrageenan was not detected in the fluorescence microscope since there is no fluorescence marker available for non-covalent staining. It is however possible to observe the $\kappa$-carrageenan-microalga systems, since $H p$ and $S p$ present autofluorescence enabling $\kappa$-carrageenan to be observed by contrast (dark areas). The images in Fig. 5a and c were obtained with a DAPIUV filter, and the ones in Fig. 5b and d with a TRITC filter. The latter enables the collection of light emitted by the sample at higher wavelengths, enhancing the contrast when microalgae are present in the gel system.

\subsection{Microalgae-starch systems}

A marked increase in $G^{\prime}$ was observed by heating $5 \%$ starch dispersions to $66.6^{\circ} \mathrm{C}$, corresponding to starch gelatinization
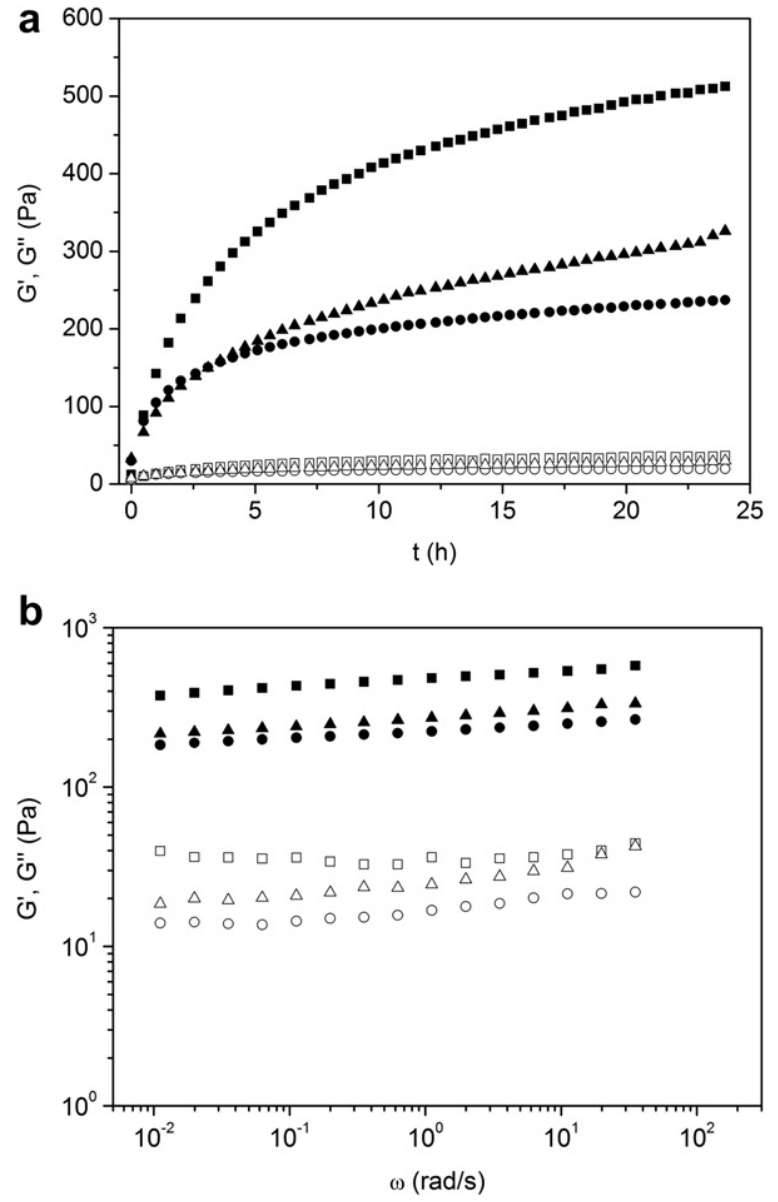

Fig. 8. Maturation kinetics curves (a) and mechanical spectra (b) at $5{ }^{\circ} \mathrm{C}$, of $4 \%$ pea protein-0.15\% $\kappa$-carrageenan gel systems ( $)$ with $0.75 \%$ Spirulina ( ) and Haematococcus ( $\mathbf{\Lambda}$ ) microalgal biomass addition. $\mathrm{G}^{\prime}$ (closed symbol), $\mathrm{G}^{\prime \prime}$ (open symbol). 

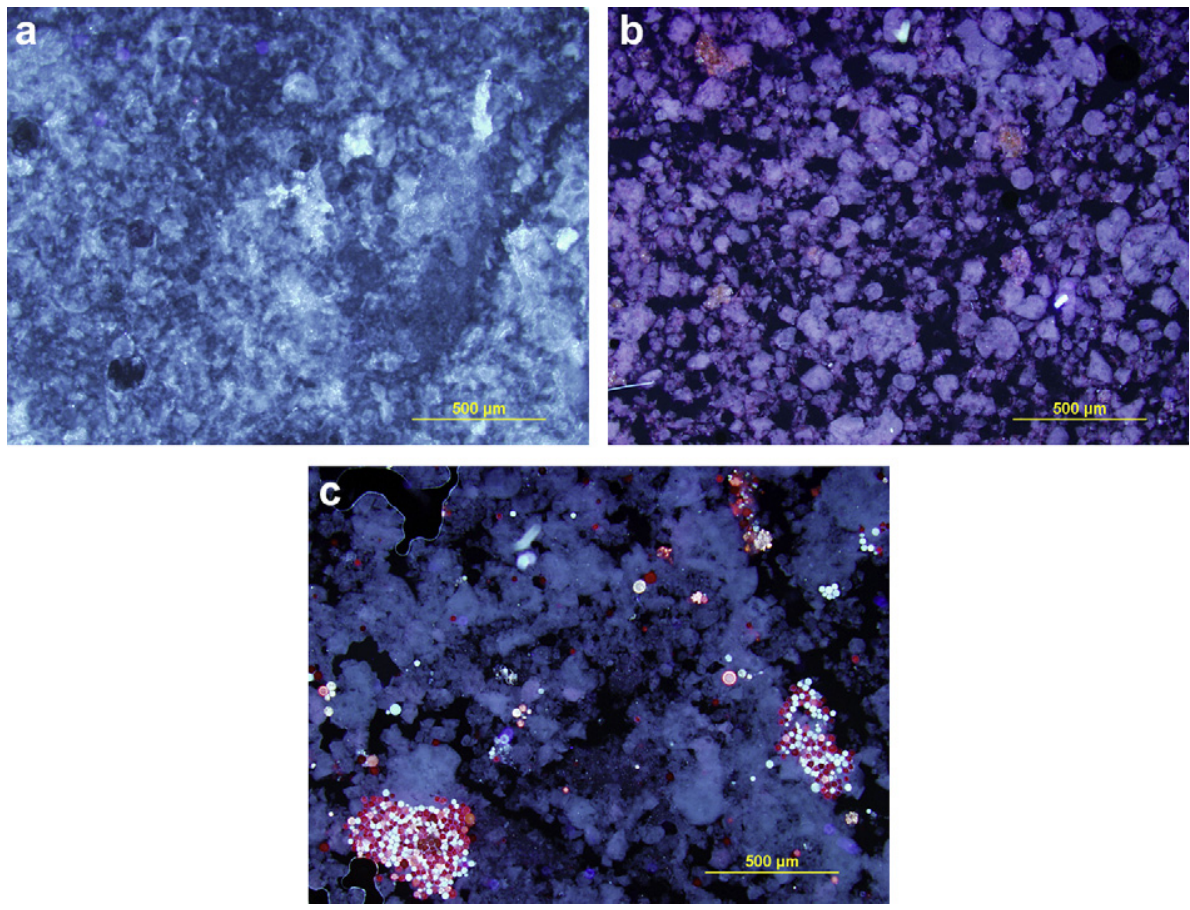

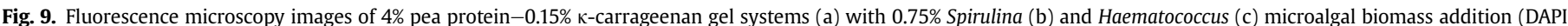
filter).

(Fig. 6a). This phenomenon is related to the swelling of the starch granules, and subsequent amylose solubilization, which causes an increase in the system's viscosity (Morris, 1990). The addition of Haematococcus and Spirulina to this system causes a slight increase in the gelatinization temperature to $70.2{ }^{\circ} \mathrm{C}$ and $73.8^{\circ} \mathrm{C}$, respectively. This indicates that microalgal biomass interferes with the starch gelatinization process perhaps by competing for water binding sites during the granules' hydration process.

In the case of Haematococcus-starch systems, this setback was overcome in the cooling ramp, resulting in a strongly maturated gel, with $G^{\prime}$ and $G^{\prime \prime}$ values higher than the simple starch gel (Fig. 6a). This can be related to a concentration effect of starch as a result of exclusion from the microalgae domain. It is also expected that Haematococcus high fat content (41\%) can play a significant role in the gels' rheological properties, as discussed previously for microalgae-pea protein systems (Section 3.1).

Alternatively, Spirulina-starch systems, presented much lower $G^{\prime}$ values than the control sample. This is in accordance with previous studies which reported the formation of weaker gels when Spirulina was added to pea protein/ $\kappa$-carrageenan/starch mixed gels, particularly for faster gel setting conditions (Batista, Gouveia, et al., 2008; Batista, Nunes, et al., 2008). Microscope images (Fig. 7) show large particles of microalgae that could imprint discontinuities in the starch network, especially in the case of Spirulina, leading to a more fragile gel structure. Unlike the other microalgae studied by the authors (Batista, Gouveia, et al., 2008) Spirulina is a cyanobacteria, and therefore its prokaryotic cells lack a rigid cell wall which could lead to higher water absorption rates by its cellular components (mainly proteinaceous), destabilizing the starch gelation mechanism.

\subsection{Microalgae-pea protein- $\kappa$-carrageenan systems}

Pea protein- $\kappa$-carrageenan binary systems form well structured gels, at low concentrations for both biopolymers, suggesting a synergistic effect. The rheological behaviour of the mixed gel is

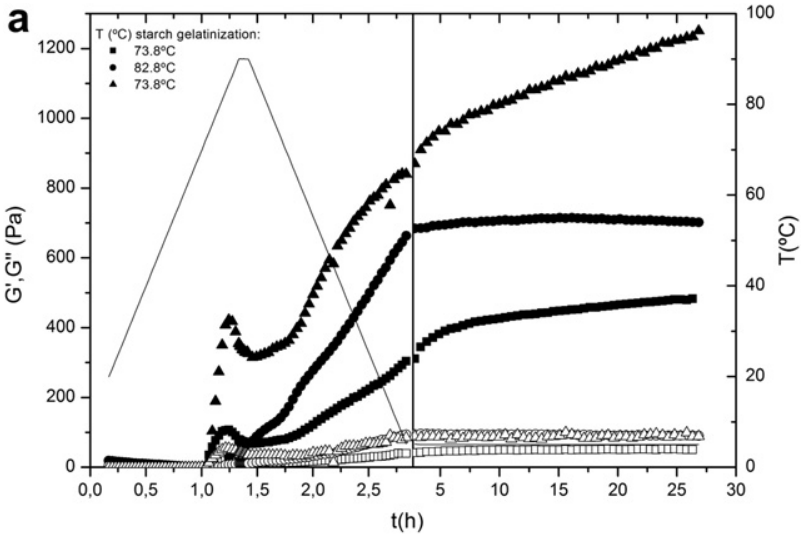

b

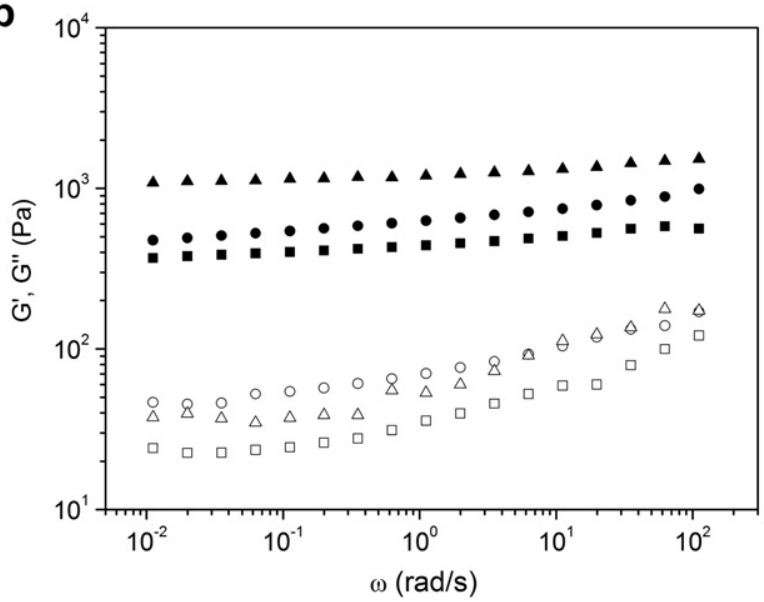

Fig. 10. Evolution of $\mathrm{G}^{\prime}$ and $\mathrm{G}^{\prime \prime}$ along thermal treatment and $24 \mathrm{~h}$ maturation at $5{ }^{\circ} \mathrm{C}$ (a); and mechanical spectra (b), of $6 \%$ pea protein-3.75\% gel systems ( $\mathbf{\square}$ ) with $1.125 \%$ Spirulina ( $)$ and Haematococcus ( $\boldsymbol{\Delta}$ ) microalgal biomass addition. $\mathrm{G}^{\prime}$ (closed symbol), $\mathrm{G}^{\prime \prime}$ (open symbol), $\mathrm{T}$ (line). 

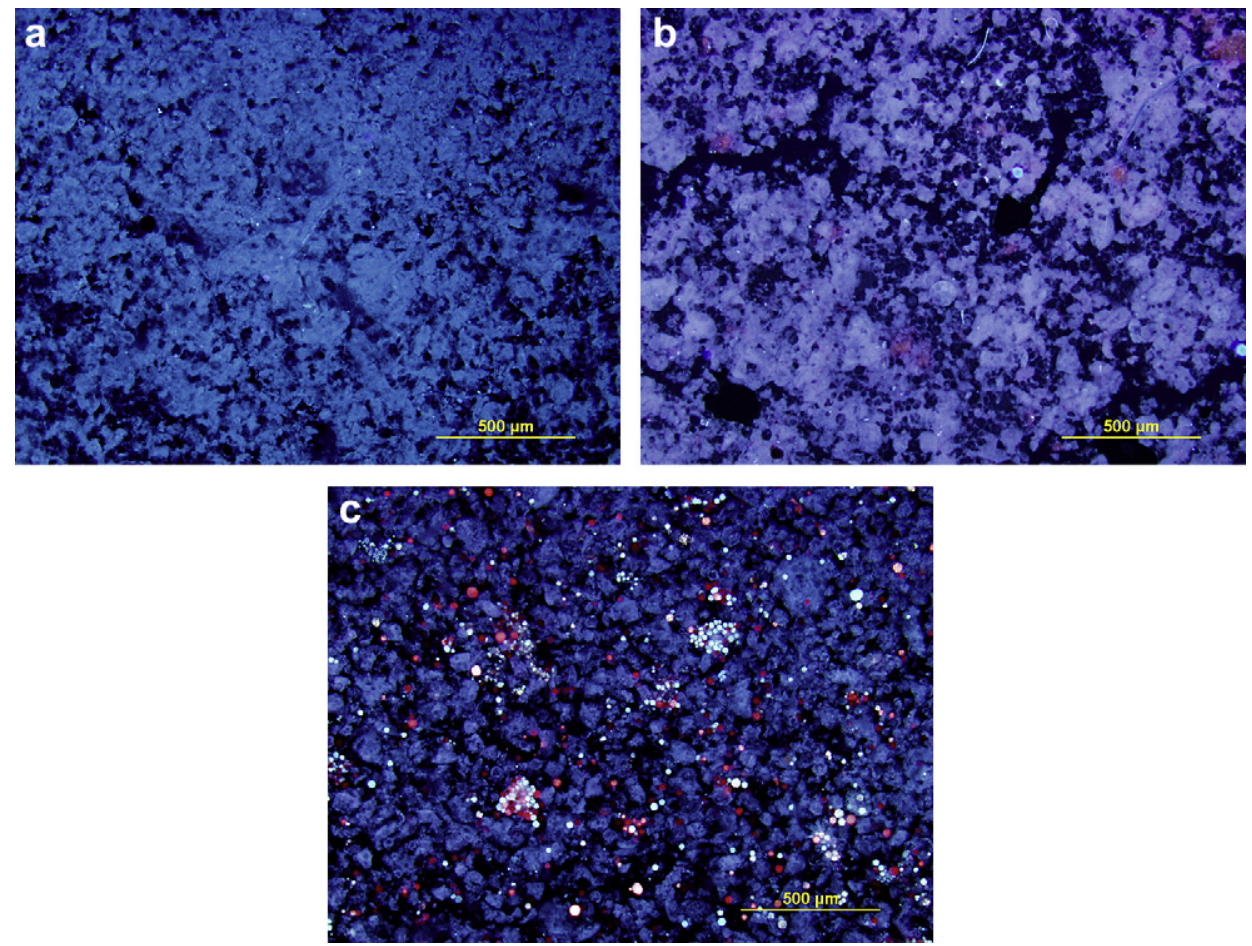

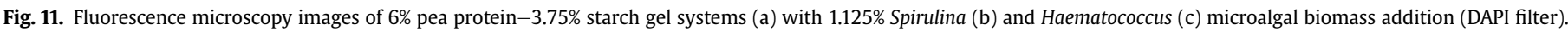

similar to the simple $\kappa$-carrageenan gel, namely the gelation temperature at $7.3^{\circ} \mathrm{C}$, the shape of the maturation curves and mechanical spectra (Fig. 8). This suggests that $\kappa$-carrageenan constitutes the continuous phase of the mixed system, which is in accordance with the findings from Nunes (2005) regarding pea protein and $\kappa$-carrageenan as being phase separated, forming two independent networks dispersed in each other.

Rheological results (Fig. 8) for pea protein/ $\kappa$-carrageenan systems are surprising, since the addition of microalgae to this binary system results in weaker gels, as opposed to their behaviour when applied separately reinforcing each biopolymer gel individually. Microscope images (Fig. 9) suggest that phase segregation becomes more evident upon microalgae addition, negatively affecting the biopolymers' interaction. Therefore, protein-polysaccharide thermodynamical incompatibility seems to be affected by the presence of microalgal biomass, which may be related to the volume exclusion effect as a consequence of macromolecular competition for space in the solution (Tolstoguzov, 2003). This could have a negative impact on the gel structure considering the low biopolymer levels (4\% pea protein, $0.15 \% \mathrm{k}$-carrageenan, $0.75 \%$ microalga) used in this study.

\subsection{Microalgae-pea protein-starch systems}

Pea protein-starch binary systems also formed well structured gels, at low concentrations for both biopolymers, suggesting a synergetic effect. When heating these systems from $20^{\circ} \mathrm{C}$ to $90^{\circ} \mathrm{C}$, a marked increase in $\mathrm{G}^{\prime}$ is observed at $73.8-75.6^{\circ} \mathrm{C}$ (Fig. 10a). This temperature corresponds to the starch gelatinization temperature, which is higher compared to the simple $5 \%$ starch gel $\left(66.6^{\circ} \mathrm{C}\right)$, as reported in Section 3.3. The effect of pea protein or Spirulina (Section 3.3) addition to starch gels is characterized by similar gelatinization temperatures. This suggests that hydration of starch granules' is impaired by pea protein and Spirulina to the same extent, demonstrating that Spirulina's protein fraction should be competing with starch granules for hydration as in Spirulina-starch gelling systems.
Pea protein/starch systems presented stronger gels in the presence of both microalgae. Haematococcus-pea protein-starch systems presented starch gelatinization at $73.8^{\circ} \mathrm{C}$ (no effect from $\mathrm{Hp}$ addition) and resulted in a stronger gel with increasing viscoelastic functions (even after $24 \mathrm{~h}$ maturation) (Fig. 10). The addition of Spirulina retarded starch gelatinization to $81-83^{\circ} \mathrm{C}$, and the gel seems fully maturated before the $24 \mathrm{~h}$ period, presenting higher $\mathrm{G}^{\prime}$ values when compared to the control gel.

From Section 3.3, a destabilizing effect was noted after Spirulina addition to the starch gel. However, the pea protein-starch synergistic effect in microalgae-pea protein-starch systems seem to be stronger than the Spirulina-starch destabilizing mechanism, resulting in gels with higher viscoelastic properties (Fig. 10).

Microscope images (Fig. 11) present densely packed continuous structures, which are in accordance with the rheological results. From these results it seems clear that protein-polysaccharide interaction plays a dominant role on the development of the gel microstructure, and will determine the extent and direction of the microalgae addition effect.

\section{Conclusions}

The addition of Spirulina and Haematococcus to biopolymer gelled systems, induced significant changes in the gels' rheological behaviour and microstructure. Haematococcus induced a general structural reinforcement action which may be related to its high fat content (41\%) (Batista, Gouveia, et al., 2008), considering that fat droplets can act as active filler particles embedded in the gel matrix as observed for milk gelled systems. Spirulina addition also resulted in stronger gel systems (but always lower than Haematococcus) except in the case of starch, where it seems to negatively affect the gelatinization process. This could be related to competition for water binding sites by Spirulina protein molecules, hindering the hydration of starch granules.

For all the systems studied, it was observed that protein and polysaccharide biopolymers - alone or in binary combinations - 
are responsible for the formation of the gel structure and resulting rheological behaviour. In most cases, microalgae seem to be embedded in the gel's network, causing denser microstructures with improved rheological parameters. However, the fact that microalgal biomass contains significant amounts of ions means that this should also have a significant impact on the biopolymers' interaction associated with the gelling mechanism, particularly in the case of k-carrageenan gels.

Fluorescence optical microscopy proved to be a simple and effective technique to observe these materials' microstructures, with microalgae being easily detected due to their natural pigments' autofluorescence. The microscopy results correlated well and supported the rheological findings.

\section{Acknowledgements}

This work is part of a research project "Pigments, antioxidants and PUFA's in microalgae based food products - functional implications" (PTDC/AGR-ALI/65926/2006) sponsored by Fundação para a Ciência e a Tecnologia (FCT). A.P. Batista acknowledges the PhD research grant from FCT (SFRH/21388/BD/2005), and Patricia Fradinho for Technical Support.

\section{References}

Batista, A. P., Gouveia, L., Nunes, M. C., Franco, J. M., \& Raymundo, A. (2008). Microalgae biomass as a novel functional ingredient in mixed gel systems. In P. A. Williams, \& G. O. Phillips (Eds.), Gums and stabilisers in the food industry, Vol. 14 (pp. 487-494). RSC Publishing.

Batista, A. P., Nunes, M. C., Fradinho, P., Gouveia, L., Sousa, I., Raymundo, A., et al. (2009). Haematococcus pluvialis microalga biomass in mixed gel systems rheological characterization under different gel setting conditions. In P. Fischer, M. Pollard, \& E. J. Windhab (Eds.), Proceedings of the 5th international symposium on food rheology and structure (pp. 628-629). Zurich: ETH.

Batista, A. P., Nunes, M. C., Gouveia, L., Sousa, I., Raymundo, A., \& Franco, J. M. (2008). Influence of gel setting conditions on the linear viscoelastic properties of multicomponent gels with microalgal biomass addition. In A. Guerrero, J. Muñoz, \& J. M. Franco (Eds.), Rheology in product design and engineering (pp. 99-102). Madrid: GER/RSEQ.

Batista, A. P., Portugal, C. A. M., Sousa, I., Crespo, J. G., \& Raymundo, A. (2005). Accessing gelling ability of vegetable proteins using rheological and fluorescence techniques. International Journal of Biological Macromolecules, 36, 135-143.

Belay, A. (2008). Spirulina (Arthrospira): production and quality assurance. In M. E. Gershwin, \& A. Belay (Eds.), Spirulina in human nutrition and health (pp. 1-26). CRC Press.

Chen, Y., Liao, M. L., \& Dunstan, D. E. (2002). The rheology of $\mathrm{K}^{+}-\kappa$-carrageenan as a weak gel. Carbohydrate Polymers, 50,109-116.

Clark, A. H., Kavanagh, G. M., \& Ross-Murphy, S. B. (2001). Globular protein gelation - theory and experiment. Food Hydrocolloids, 15, 383-400.
Fradique, M., Batista, A. P., Nunes, M. C., Gouveia, L., Bandarra, N. M., \& Raymundo, A. (2010). Chlorella vulgaris and Spirulina maxima biomass incorporation in pasta products. Journal of the Science of Food and Agriculture, 90, 1656-1664.

Gouveia, L., Batista, A. P., Miranda, A., Empis, J., \& Raymundo, A. (2007). Chlorella vulgaris biomass used as colouring source in traditional butter cookies. Innovative Food Science and Emerging Technologies, 8, 433-436.

Gouveia, L., Batista, A. P., Raymundo, A., \& Bandarra, N. M. (2008). Spirulina maxima and Diacronema vlkianum microalgae in vegetable gelled desserts. Nutrition and Food Science, 38, 492-501.

Gouveia, L., Batista, A. P., Raymundo, A., Sousa, I., \& Empis, J. (2006). Chlorella vulgaris and Haematococcus pluvialis biomass as colouring and antioxidant in food emulsions. European Food Research and Technology, 222, 362-367.

Gouveia, L., Coutinho, C., Mendonça, E., Batista, A. P., Sousa, I., Bandarra, N. M., et al. (2008). Sweet biscuits with Isochrysis galbana microalga biomass as a functional ingredient. Journal of the Science of Food and Agriculture, 88, 891-896.

Gouveia, L., \& Empis, J. (2003). Relative stabilities of microalgal carotenoids in microalgal extracts, biomass and fish feed: effect of storage conditions. Innovative Food Science and Emerging Technologies, 4, 227-233.

Houzé, G., Cases, E., Colas, B., \& Cayot, P. (2005). Viscoelastic properties of acid milk gel as affected by fat content at low level. International Dairy Journal, 15, 1006-1016.

Kobayashi, M., Kakizono, T., Nishio, N., Nagai, S., Kurimura, Y., \& Tsuji, Y. (1997). Antioxidant role of astaxanthin in the green alga Haematococcus pluvialis. Applied Microbiology and Biotechnology, 48, 351-356.

Lucey, J. A., Munro, P. A., \& Singh, H. (1998). Rheological properties and microstructure of acid milk gels as affected by fat content and heat treatment. Journal of Food Science, 63, 660-664.

Morris, E. R., Rees, D. A., \& Robinson, G. (1980). Cation-specific aggregation of carrageenan helices: domain model of polymer gel structure. Journal of Molecular Biology, 138, 349-362.

Morris, V. J. (1990). Starch gelatinization and retrogradation. Trends in Food Science and Technology, 1, 2-6.

Nickerson, M. T., \& Paulson, A. T. (2004). Rheological properties of gellan, k-carrageenan and alginate polysaccharides: effect of potassium and calcium ions on macrostructure assemblages. Carbohydrate Polymers, 58, 15-24.

Nunes, M. C. H. (2005). Interações proteína/polissacárido em géis proteicos de origem vegetal. PhD thesis, Technical University of Lisbon.

Nunes, M. C., Raymundo, A., \& Sousa, I. (2006a). Rheological behaviour and microstructure of pea protein/ $\kappa$-carrageenan/starch gels with different setting conditions. Food Hydrocolloids, 20, 106-113.

Nunes, M. C., Raymundo, A., \& Sousa, I. (2006b). Gelled vegetable desserts containing pea protein, $\kappa$-carrageenan and starch. European Food Research and Technology, 222, 622-628.

Raymundo, A., Gouveia, L., Batista, A. P., Empis, J., \& Sousa, I. (2005). Fat mimetic capacity of Chlorella vulgaris biomass in oil-in-water food emulsions stabilised by pea protein. Food Research International, 38, 961-965.

Rochas, C., \& Landry, S. (1987). Molecular organization of kappa carrageenan in aqueous solution. Carbohydrate Polymers, 7, 435-447.

Todd-Lorenz, R., \& Cysewski, G. R. (2000). Commercial potential for Haematococcus microalgae as a natural source of astaxanthin. Trends in Biotechnology, 18, 160-167.

Tolstoguzov, V. B. (2003). Some thermodynamic considerations in food formulation. Food Hydrocolloids, 17, 1-23.

Van Vliet, T., Martin, A. H., \& Bos, M. A. (2002). Gelation and interfacial behaviour of vegetable proteins. Current Opinion in Colloid and Interface Science, 7, 462-468.

Vélez-Ruiz, J. F., González-Tomás, L., \& Costell, E. (2005). Rheology of dairy custard model systems: influence of milk-fat and hydrocolloid type. European Food Research and Technology, 221, 342-347.

Vonshak, A. (1986). Laboratory techniques for the cultivation of microalgae. In A. Richmond (Ed.), CRC handbook of microalgal mass culture (pp.117-143). CRC Press. 